\title{
STUDY OF LIPID PEROXIDE AND LIPID PROFILE IN DIABETES MELLITUS
}

\section{Biochemistry}

Dr. Divya Sinha*

\section{Dr. S. R. Padmeodev}

\section{Dr. Debarshi Jana}

M.Sc., Ph.D. (Biochemistry), Department of Biochemistry, Patna Science College, Patna, Bihar. *Corresponding Author

Professor and Head of Department, Department of Biochemistry, Patna Science College, Patna, Bihar.

Young Scientist(DST), Institute of Post-Graduate Medical Education and Research, A.J.C. Bose Road, Kolkata, West Bengal, India-700020.

\section{ABSTRACT}

The study was designed to find out the correlation between lipid peroxidation, lipoprotein levels to severity and complication of diabetes mellitus. Degree of lipid peroxidation was measured in terms of malondialdehyde (MDA) along with lipid profile and blood glucose in diabetes mellitus. It is categorised into insulin dependent diabetes mellitus (IDDM), non insulin dependent diabetes mellitus (NIDDM) and diabetes mellitus(DM) with complication.

Total 112 known diabetic cases and 52 non-diabetic controls were studied. These cases were grouped as per the concentration of fasting blood glucose level i.e. controlled, poorly controlled, and uncontrolled group. There are significant increase in the lipid peroxide (MDA) and lipid profile except HDL cholesterol which is decreased, has been found in all groups as compared to controls. In NIDDM group lipid peroxidation was markedly increased than IDDM group and it was higher in DM with complications. Other finding observed was that the level of lipid peroxide increased as per the increase in concentration of blood glucose. The increase lipid peroxidation in the hyperglycemic condition may be explained, as the superoxide dismutase enzyme which is antioxidant becomes inactive due the formation of superoxide radical within the cell. Maximum lipid peroxidation leads to the damage of the tissue and organs which results into complication in diabetic cases. High levels of total cholesterol appear due to increased cholesterol synthesis. The triglyceride levels changes according to the glycemic control. The increase may be due to overproduction of VLDL-TG.

It is concluded that good metabolic control of hyperglycemia will prevent in alteration in peroxidation and the lipid metabolism, which may help in good prognosis and preventing manifestation of vascular and secondary complication in diabetes mellitus

\section{KEYWORDS}

\section{Malondialdehyde, Lipid Peroxide, Diabetes Mellitus.}

\section{INTRODUCTION}

The first systematic description was written by the Arelaeus of cappadosis in Asia minor, probably in the 1st century AD, the disease as "A melting down of flesh into the urine". The discovery by Van Mering and Minikowaski in 1889 that pancreactomy causes a metabolic disorder called Diabetes mellitus is the result of insulin deficiency. It is characterized by either the absence of insulin that is NIDDM-Type 1 or which is insensitive to the insulin that is IDDM or type II. It is a complex disease where the carbohydrate and fat metabolism is impaired ${ }^{(1)}$. Insulin affects many sites of mammalian lipid metabolism. It stimulates synthesis of fatty acid in liver adipose tissue and in the intestine. The insulin has also been reported to increase the cholesterol synthesis. The activity of lipoprotein lipase in white adipose is also increased. From this point of view the assessment of various lipid fractions and lipid peroxide in the cases of Diabetes Mellitus may be of some help in the prognosis of cases and in preventing the possibilities of complications or secondary disorders. The occurrence of free radical induced lipid peroxidation causes considerable change in the cell membrane ${ }^{(3)}$. Peroxidation of lipid membrane has been related to the pathogenesis of many degenerative diseases, such as atherosclerosis, oxidative damage to DNA, aging. carcinogenesis, sickle cell disease and Diabetes Mellitus etc. ${ }^{(4)}$. Thus, the lipid peroxide in the blood provides useful information for the prognosis of diabetes in which secondary disorders are often fatal ${ }^{(5)}$.

\section{AIM OF THE STUDY}

The study was undertaken to evaluate the relationship of lipid peroxide with lipids, lipoprotein fraction and severity of diabetes to find the possibilities of preventing complications or secondary disorders.

\section{MATERIALAND METHODS}

The fasting and postprandial blood sample, $2 \mathrm{ml}$ in floride bulb for sugar estimation and $5 \mathrm{ml}$ in plain bulb for lipid peroxide and lipid profile estimation were collected from the cubital vein. Serum was separated by centrifugation at $3000 \mathrm{rpm}$ for 10 minutes. Plasma was separated within 30 minutes of sample collection by centrifugation at $3000 \mathrm{rpm}$ for 1-2 minutes (for sugar and lipid peroxide estimation). Assay for lipid peroxide level in plasma, (Esterbauer and Steinberg et at., 1989). Malondialdehyde (MDA) was assayed as a marker of lipid peroxidation using colorimetric reaction, which uses 1- methyl- 2phenylindole as chromogen. Condensation of one molecule of malondialdehyde with two molecule of 1-methyl -2-phenylindole under acidic condition results in the formation of a chromophore with an absorbance of maximum at $586 \mathrm{~nm}$. To determine specifically lipid peroxide in plasma, they are precipitated along with plasma proteins to remove water-soluble MPI reactive substances.

The level of lipid peroxide is expressed in term of malondialdehyde. Since the malondialdehyde is unstable, tetramethoxypropane which is converted quantitatively to MDA in the reaction procedure is used as standard.

\section{Procedure}

1. $7.6 \mathrm{nM}$ solution of 1-methyl-2-phenylindole was prepared immediately prior to use in $33 \%$ methanol in acetonitrile.

2. 6501 aliquot of 1-methyl-2-phenylindole was placed in each test tube to which 2001 of plasma was added.

3. The tube were mixed well and 1501 of $10 \mathrm{MHCL}$ was added

4. After mixing once more, the tubes were sealed and incubated for 60 $\min$. at $45^{\circ} \mathrm{C}$

5. After incubation, the tubes were chilled on an ice bath and spun at $10,000 \mathrm{rpm}$ for $5 \mathrm{~min}$ to remove the debris.

6 . The absorbance at $586 \mathrm{~nm}$ was measured and the substracted from the blank value obtained by replacing plasma with water.

7. A calibration graph was prepared using $2 \mathrm{~mol} / \mathrm{L}, 4 \mathrm{~mol} / \mathrm{L}, 6 \mathrm{~mol} / \mathrm{L}$ and $8 \mathrm{~mol} / \mathrm{L}$ 1,1,3,3-tetramethoxypropane in $20 \mathrm{nM}$ Tris HCL, buffer $\mathrm{pH} 7.4$.

\section{Blood Sugar-}

Enzymatic , GOD-POD, endpoint colorimetric, single reagent chemistry. (Trinder P and Teitz N. W. by autospan kit method).

\section{Total Cholesterol-}

Enzymatic endpoint Kit method, Randox Laboratory Ltd.

\section{Serum Triglycerides-}

Enzymatic kit method - Transasia -Bio-medicals Ltd. (MeGowan et al., Fossati et al. and wako et al.).

\section{HDL cholesterol-}

CHOD-POD kit method (Boehringer Mannheim Ltd.).

LDL and VLDL cholesterol- Burstein M. et al. and Lape-Virella et al. 
RESULT

The study was carried out in 112 known diabetic cases and 52 healthy non-diabetic control subjects in the department of Biochemistry, Patna Science College, Patna, Bihar.

Incidence of diabetes mellitus is $57.14 \%$ in age group 40-49 yrs, followed by $24.11 \%$ in above 60 yrs age group comparatively incidence of diabetes is low in age group 30-39 yrs.

The mean value of plasma lipid peroxide is high in Diabetic cases when compared to control group and increase is statistically significant $(\mathrm{p}<0.01)$.

Mean value of total Cholesterol, serum triglyceride, LDL- Cholesterol and VLDL-Cholesterol in diabetic group is increased compared to control group $(\mathrm{p}<0.01)$.

Mean value of serum HDL- Cholesterol is decreased in diabetic group compared to control and decreased is statistically significant $(p<0.01)$.

Table 1 : Age And Sex Distribution

\begin{tabular}{|l|l|l|l|l|}
\hline \multirow{2}{*}{ Age } & Sex & & Total & Percentage \\
\cline { 2 - 4 } & Male & Female & & \\
\hline $30-39$ & 15 & 06 & 21 & 18.75 \\
\hline $40-49$ & 38 & 26 & 64 & 57.14 \\
\hline 60 and above & 14 & 13 & 27 & 24.11 \\
\hline Total & 67 & 45 & 112 & 100.00 \\
\hline
\end{tabular}

Table 2 : Lipid Peroxide Level In Plasma Of Various Diabetes Mellitus Groups

\begin{tabular}{|l|l|l|l|}
\hline \multirow{2}{*}{ Group } & \multicolumn{3}{|l|}{ Plasma Lipid Peroxide (mmol/l) } \\
\cline { 2 - 4 } & Mean & S.D. & P value \\
\hline Control (52) & 3.40 & \pm 70.26 & \\
\hline IDDM (38) & 4.56 & \pm 0.62 & $\mathrm{P}<0.01$ \\
\hline NIDDM (74) & 4.92 & \pm 0.78 & $\mathrm{P}<0.01$ \\
\hline DM with complications & 5.31 & \pm 0.49 & $\mathrm{P}<0.01$ \\
\hline
\end{tabular}

Table 3 : Relationship Of Lipid Peroxidation, According To Blood Glucose Level

\begin{tabular}{|l|l|l|l|}
\hline $\begin{array}{l}\text { Group of Diabetes according to } \\
\text { blood glucose level }\end{array}$ & $\begin{array}{l}\text { No. of } \\
\text { cases }\end{array}$ & $\begin{array}{l}\text { Lipid } \\
\text { Peroxide }\end{array}$ & P value \\
\hline $\begin{array}{l}\text { Group A : Fasting blood sugar } \\
\text { below 130 mg/dl (90-130 mg/dl) }\end{array}$ & 32 & $4.12 \pm 0.38$ & $\mathrm{P}<0.01$ \\
\hline $\begin{array}{l}\text { Group B : Fasting blood sugar } \\
\text { below 180 mg/dl (131-180 mg/dl) }\end{array}$ & 46 & $4.62 \pm 0.56$ & $\mathrm{P}<0.01$ \\
\hline $\begin{array}{l}\text { Group C : Fasting blood sugar } \\
\text { above 180 mg/dl (above 180 } \\
\text { mg/dl) }\end{array}$ & 34 & $4.98 \pm 0.72$ & $\mathrm{P}<0.01$ \\
\hline Group D : Control & 52 & $3.74 \pm 0.26$ & $\mathrm{P}<0.01$ \\
\hline
\end{tabular}

Table 4 : Mean Value Of Lipid Peroxide And Lipid Fractions In

Controls And Diabetic Cases

\begin{tabular}{|l|l|l|}
\hline $\begin{array}{l}\text { Lipid peroxide and lipid } \\
\text { fractions }\end{array}$ & Control $(\mathbf{n = 5 2 )}$ & $\begin{array}{l}\text { Diabetics } \\
(\mathbf{n = 1 1 2})\end{array}$ \\
\hline Lipid peroxide $(\mathrm{mmol})$ & $3.74 \pm 0.26$ & $4.93 \pm 0.63$ \\
\hline Total cholesterol $(\mathrm{mg} / \mathrm{dl})$ & $188.65 \pm 24.61$ & $282.00 \pm 46.23$ \\
\hline Triglyceride $(\mathrm{mg} / \mathrm{dl})$ & $110.46 \pm 36.12$ & $26.26 \pm 11.72$ \\
\hline HDL-cholesterol $(\mathrm{mg} / \mathrm{dl})$ & $4.93 \pm 0.63$ & $232.12 \pm 46.23$ \\
\hline LDL-cholesterol $(\mathrm{mg} / \mathrm{dl})$ & $174.36 \pm 86.67$ & $44.86 \pm 16.46$ \\
\hline VLDL-cholesterol $(\mathrm{mg} / \mathrm{dl})$ & $152.85 \pm 48.93$ & $38.30 \pm 18.96$ \\
\hline
\end{tabular}

Table 5 : Ratio Between Lipid Peroxide And Lipid Fractions In Control And Diabetics

\begin{tabular}{|l|l|l|}
\hline Parameters Ratio & Control & Diabetics \\
\hline LP : Total cholesterol & 50.44 & 35.89 \\
\hline LP : Triglyceride & 14.41 & 29.53 \\
\hline LP : HDL- Cholesterol & 07.01 & 57.31 \\
\hline LP : LDL - cholesterol & 35.36 & 09.06 \\
\hline LP : VLDL-cholesterol & 31.00 & 07.76 \\
\hline
\end{tabular}

\section{The Ratio Between Lipid Peroxide:}

Total Cholesterol is higher in diabetic cases than control. The ratio of lipid peroxide : HDL-Cholesterol is lower in diabetic cases than control, whereas the ratio of lipid peroxide : LDL-Cholesterol and VLDL-Cholesterol is higher in diabetic cases than control group. In this study group there is significant correlation between lipid peroxide concentration and lipid fractions except HDL-cholesterol.

DISCUSSION

The toxic material produced by an activated phagocytes during reaction can cause maximal damage to the membrane because they are active in the lipid phase. The damaging effect of elevated toxic radical are due to an increase in the formation of superoxide radicals within cells which causes inactivation of superoxide dismutase enzyme in hyperglycemic condition. This affects the tissue damage and secondary disorder in diabetes mellitus. Normally free radicals produce in metabolism are effectively scavenged. Oxidative stress occur when there is an imbalance between production and scavenging. Increased in lipid peroxidation in diabetes mellitus is due to excess formation of free radicals. Glycosylated protein, autooxidation, reduced superoxide dismutase enzyme and ascorbic acid and lack of reduced glutathione are other causes for oxidative stress.

In the present study all groups of diabetes mellitus shows statistically significant increase in serum lipid peroxide levels. Few of the most probable causes for the increased lipid peroxide level in diabetes mellitus are

1. In the diabetes mellitus abnormal increased levels of lipid lipoprotein and lipid peroxides in plasma may be due to the abnormal lipid metabolism ${ }^{(11)}$. Maximum increase in lipid peroxide was found in group of diabetes mellitus with complication. Elevated levels of lipid peroxide in diabetes mellitus may be due to the alteration of function of erythrocytes membrane. This inhibit the activity of superoxide dismutase enzyme leading to accumulation of superoxide radicals which cause the maximum lipid peroxidation and tissue damage in diabetes $^{(12)}$

2. Increase lipid peroxide may be due to the increased glycation of protein in diabetes mellitus. The glycated protein might themselves act as a source of free radicals. There is a clear association between lipid peroxide and glucose concentration, which may be also thought to play a role in increased lipid peroxidation in diabetes mellitus.

3. A deficiency of the antioxidant activity of superoxide dismutase and glutathione peroxidase has been related to higher concentration of peroxide. There may be imbalance between production and scavenging of free radical produced due to the lack of antioxidant system.

4. Mitochondria and microsomal membrane contain relatively large amount of polyunsaturated fatty acid in their phospholipid. These include fatty acid with 2, 4, 5 and 6 double bonds. Due to the presence of 3 or more double bond they are likely to be more sensitive for attack by free radicals resulting in high lipid peroxidation. Hence the rate of peroxidation may be high causing the higher concentration of lipid peroxides and free radical in diabetes mellitus.

5. Peroxidation of apolipoproteins may affect the lipoprotein metabolism. It is suggested that apo-A has an antioxidant effect, but due to the peroxidation the antioxidant property of apo-A is lost.

Higher level of lipid peroxides were observed in diabetic subject with vascular complication. This increase in lipid peroxide may be due to the increased activity of the free radical formation. Free radical interact in arachidonic acid metabolism, forming a toxic endoperoxidase. The lipid peroxide formed stimulates the cyclooxygenase and prostaglandin and thromboxane synthesis. This will cause increased platelets aggregation, leading to vascular complications ${ }^{(13)}$. We have found that serum cholesterol is increased in all group of diabetes when compared with the controls. Some of the possible reason of higher concentration of serum cholesterol in diabetes may be attributed to decrease muscular exercise or inhibition of cholesterol catabolism.

It has been suggested that the increase in triglyceride may be due to insulin deficiency which results faulty glucose utilization, causes hyperglycemia and mobilization of fatty acids from adipose tissue. In diabetes blood glucose is not utilized by tissue resulting in hyperglycemia. The fatty acid from adipose tissue are mobilized for energy purpose and excess fatty acid are accumulated in the liver, Which are converted to triglyceride. The present study indicate that insulin increases the number of LDL receptor, so chronic insulin deficiency might be associated with a diminished level of LDL receptor. This causes the increase in LDL particles and result in the increase in LDL-cholesterol value in diabetes mellitus.

High level of cholesterol, triglyceride, LDL-cholesterol and low HDLcholesterol may be due to the obesity, increase calorie intake and lack of muscular exercise in the cases of diabetes mellitus. The estimation 
of lipid peroxide along with other lipid profile in the diabetes mellitus is very useful as it may serve as a useful monitor to judge the prognosis of the patient. The detection of risk factor in the early stage of the disease will help the patient to improve and reduce the morbidity rate.

\section{REFERENCES}

Altamer, E., Vendemisle, G. and Chicco, D. (1991). Increased lipid peroxidation in Type-II poorly control Diabetic cases. Diabete. Etab.18 (4), 264-671.

2. Jain, A.P and Gupta, D.P. (1980). Study of blood lipids in Diabetics without any manifest vascular complications. J. Dia. Asso. Ind. Vol. XX, 29-34.

3. Agrawal, S. Banerjee, S. and Chatterjee, S.N. (1985). Effects of oxygen on ferrous Agrawal, S., Banerjee, S. and Chatterjee, S.N. (1985). Effects of oxygen on ferrous Biophysics. 21,331-334.

4. Chattergee, S.N., Agrawal, S. and Amitkumar (1988). Membrane lipid peroxidation and its pathological consequence. Ind. J. of Biochem and Biophysics. 25, 31

5. Tappel, A.L. (1973). Lipid peroxidation damage to cell components. Clinical pathology.Federation proceeding 32 (8), 1870-1874.

6. Yuzo, Sato, Migishi, Hotta and Nabuo, Sakamoto (1979). Lipid peroxide level in plasma of Diabetic cases. Biochemical Medicine 21, 104-107.

. Nishigaki, Ikua, Masako, Hagihara and Hiroshi Tsunekawo (1981). Lipid peroxide level and serum lipoprotein fractions in Diabetics cases. Biochemical Medicine 25, 373-378.

8. Chandilia, H.B., Talwalkar, B.S. and Rajha, B.S. (1988). Lipid profiles in Diabetes Chandilia, H.B., Talwalkar, B.S. and Rajha, B.S. (1988). Lipid profiles in Diabetes mellitus. J. Dia. Assoc. India 21, 155

9. Stalenhoef, A.F.H., Demacker, P.N.M. and Lutterman, J.A. (1978). High Density lipoprotein and maturity onset Diabetes. Prog. Lipid Res. 32, 1-24.

10. Taniguchi, Naoyuki (1992). Clinical significance of superoxide dismutase, Change in aging, Diabetes, Ischemia and Cancer. Advance in clini. chem, 29, 1-47.

11. Suckling, Keith E. and Brian, Jackson (1993). Animal Models of Human lipid Metabolism. Prog lipid. Res. 32, 124

12. Freitas, J.P., Filipe, P.M. and Radrigo, F.G. (1997). Lipid peroxidation in Type-II normolipidemic diabeticcases Diabetes. Res. Practy. 36(2), 71-75.

13. Velazquez, E., Winocour, P.H., Kestenen, P. et al. (1991). Relation of lipid peroxide to macrovascular diseases in type-II Diabetes. Diabetic Medicine 8, 752-758.

14. Shih, K.C., Kwak, C.F. and Hwa, C.M. (1997). Acipimox attenuates hypertriglyceredemia in Dislipidemic Non-insulin dependent diabetes mellites cases without perturbation of insulin sensitivity and glycemic control. Diabetic. Res. clin. pract. 36(2), 113-119.

15. Das, Siddartha, Samal, Khitish Chandram and Tripathy, Bibhuti Bhashnt (1992). Factors influencing plasma lipids and lipoprotein cholesterol in Indian NIDDM. J. Dia. Assoc. Ind. 32 (2).

16. Yogi, K. et al. (1999). Lipid peroxide and human diseases. Chemistry and Physics of Lipid 45, 337-351. 